\title{
Pilot study of closing volume in byssinosis
}

\author{
R. P. FAIRMAN, J. HANKINSON, H. IMBUS, N. L. LAPP, and \\ W. K. C. MORGAN \\ Appalachian Laboratory for Occupational Respiratory Diseases, National Institute for \\ Occupational Safety and Health, and Department of Medicine, West Virginia University School \\ of Medicine, and Burlington Industries.
}

\begin{abstract}
Fairman, R. P., Hankinson, J., Imbus, H., Lapp, N. L., and Morgan, W. K. C. (1975). British Journal of Industrial Medicine, 32, 235-238. Pilot study of closing volume in byssinosis. A study of the relative sensitivities of forced expiratory volume in one second $\left(\mathrm{FEV}_{1}\right)$, maximal midexpiratory flow (MMF), and closing volume (CV) in the detection of subjects with byssinosis was carried out in a North Carolina cotton mill. Altogether 35 workers participated in the study. Of these, nine showed a decline in FEV 1 of $10 \%$ or more during the first work shift that followed the weekend break. Twelve subjects showed a decrease in MMF of $15 \%$ or more. In contrast only six workers exhibited a $10 \%$ increase in closing capacity, while ten showed a $10 \%$ increase in CV. Recent evidence of the magnitude of variability in closing volume manoeuvres suggests that our chosen level of change was too low. A $40 \%$ change in $C V$ would have identified only five subjects. CV is a more complex manoeuvre for the subject being tested and for the technician to perform, is more time consuming, and is subject to greater variation. To have any advantage over spirometry, $\mathrm{CV}$ would have to be appreciably more sensitive. Our study suggests that it is not. However, the MMF may prove to be more sensitive than the $\mathrm{FEV}_{1}$ in the detection of byssinosis.
\end{abstract}

The measurement of closing volume (CV) has been proposed as a means whereby respiratory disease can be detected early in its course while it is still reversible (McCarthy et al., 1972). CV has been shown to be abnormal in asymptomatic cigarette smokers and in asthmatics whose standard spirometric tests are within normal limits (Buist, 1973; McCarthy and Milic-Emili, 1973; McFadden et al., 1974). It therefore occurred to us that the measurement of $\mathrm{CV}$ may be more sensitive than the forced expiratory volume in one second $\left(F E V_{1}\right)$ in the detection of subjects with early byssinosis. With this in mind, we conducted a pilot study in a North Carolina cotton mill to compare the relative sensitivities of $F E_{1}$, maximal midexpiratory flow (MMF) and CV.

\section{Material and methods}

The study was carried out in a North Carolina cotton mill using the Medical Research Council (MRC) questionnaire, and standard tests of ventilatory capacity before and after a shift, had disclosed an appreciable prevalence of the condition. Altogether 35 cotton mill operatives were selected for study, of whom about half at any one time had symptoms suggesting byssinosis. Of these, one was employed in picking, nine in carding, ten in spinning, and fifteen in weaving. There were six women spinners and six women weavers. All the rest were men.

Each subject had Schilling's modification of the MRC questionnaire administered (Roach and Schilling, 1960). In addition all participants performed spirometry and closing volume half an hour to an hour before the first shift that followed the weekend break. These manoeuvres were repeated after the subject had been working for a period of six to eight hours. Smokers were asked to refrain from smoking for at least half an hour before each test to reduce the effect of cigarettes.

Ventilatory capacity

At least three reproducible forced expiratory volume manoeuvres were performed and recorded on a Jones 
in which byssinosis is still a problem. Previous surveys Pulmonor (Jones Medical Instrument Company, 200 Windsor Drive, Oak Brook, Illinois 60521) ${ }^{1}$. The largest forced expiratory volume in one second $\left(F E V_{1}\right)$ and the largest forced vital capacity (FVC) were accepted as the patient's values. A decline in $\mathrm{FEV}_{1}$ of $10 \%$ during the shift was felt to be clinically significant and to suggest the presence of byssinosis. The maximal mid-expiratory flow (MMF) was also measured (Leuallen and Fowler, 1955), but since this index of ventilatory capacity is subject to greater variation, a decrement of $15 \%$ was accepted as an indication of the presence of byssinosis.

\section{Closing volume}

The subjects performed a modified single breath nitrogen closing volume manoeuvre before and after the same work shift in which they performed spirometry. The patient was seated and fitted with a nose clip. He was instructed to take a deep breath, seal his lips around the mouth piece, and exhale into the spirometer. After reaching residual volume, a 3-way valve was turned so that he inspired $100 \%$ oxygen from the bag in a box until his lungs were filled completely. The patient then exhaled slowly and evenly into the spirometer to residual volume. Both inspiratory and expiratory flow rates were monitored with a visual display and patients were instructed to maintain an inspiratory flow rate of approximately $0.25 \mathrm{1} / \mathrm{s}$ and an expiratory rate below $0.5 \mathrm{l} / \mathrm{s}$. The procedure was repeated at least twice but as often as necessary to obtain two acceptable tracings using the criteria described in Suggested Standardized

${ }^{1}$ Mention of brand names or products does not constitute endorsement by the USA Public Health Service.
Procedures for Closing Volume Determination (National Heart and Lung Institute, 1973). Five minutes were allowed between manoeuvres. Gas was sampled continuously at the mouth by a rapidly responding nitrogen analyzer (Medical Science Electronics Nitralyzer Model 605, St Louis, Missouri 63132). Volume and nitrogen concentration were recorded on the horizontal and vertical axes of an $x-y$ recorder (Hewlett-Packard Model 7043A, Monroeville, Pennsylvania 15146). The tracings were measured according to National Heart and Lung Institute standards and calculations made of total lung capacity (TLC), closing volume (CV), and closing capacity (CC). The vital capacities of the selected tracings had to be within $10 \%$. The mean of the two values was used in the analysis of the results, and a $10 \%$ increase over the shift was accepted as an indication of byssinosis. This value was chosen on the basis of early reports of the reproducibility of the test (Collins et al., 1973).

\section{Results}

Only two subjects gave symptoms of Grade I byssinosis. All the others denied having symptoms on this occasion. One operative was unable to perform the spirometry satisfactorily, while two were unable to follow the instructions for the $\mathrm{CV}$ manoeuvre. Satisfactory measurements were thus obtained in 32 subjects. Comparison of individual patient tracings of the largest FVC with the second largest showed that before shift only two, and after that shift only three, of our patients had greater than $10 \%$ variability in the measurement of $\mathrm{FEV}_{1}$.

TABLE 1

Distribution of Sample by Smoking Status, Sex, and Occupation

\begin{tabular}{|c|c|c|c|c|c|c|}
\hline \multirow{2}{*}{ Occupation } & \multicolumn{3}{|c|}{ Men } & \multicolumn{3}{|c|}{ Women } \\
\hline & Smokers & Ex-smokers & Non-smokers & Smokers & Ex-smokers & Non-smokers \\
\hline \begin{tabular}{ll} 
Picking & $\ldots$ \\
Carding & $\ldots$ \\
Spinning \\
Weaving and \\
\multicolumn{2}{c}{ warping }
\end{tabular} & $\begin{array}{l}1 \\
7 \\
1 \\
6\end{array}$ & $\begin{array}{l}0 \\
1 \\
2 \\
1\end{array}$ & $\begin{array}{l}0 \\
0 \\
1 \\
1\end{array}$ & $\begin{array}{l}0 \\
0 \\
4\end{array}$ & $\begin{array}{l}0 \\
0 \\
0 \\
0\end{array}$ & $\begin{array}{l}0 \\
0 \\
1\end{array}$ \\
\hline
\end{tabular}

TABLE 2

Number of SubJects showing $10 \%$ Decrease in FEV 1 , OR $15 \%$ DeCrease in MMF*

\begin{tabular}{|c|c|c|c|c|c|c|}
\hline \multirow{2}{*}{ Occupation } & \multicolumn{3}{|c|}{$F E V_{1}$} & \multicolumn{3}{|c|}{$M M F$} \\
\hline & Smokers & Ex-Smokeers & Non-smokers & Smokers & Ex-smokers & Non-smokers \\
\hline $\begin{array}{l}\text { Picking } \\
\text { Carding } \\
\text { Spinning } \\
\text { Weaving and } \\
\text { warping }\end{array}$ & $\begin{array}{l}0 / 1 \\
3 / 7 \\
1 / 5 \\
2 / 8\end{array}$ & $\begin{array}{l}\overline{0} \\
0 / 1 \\
1 / 1\end{array}$ & $\begin{array}{l}\overline{-} \\
1 / 2 \\
1 / 5\end{array}$ & $\begin{array}{l}0 / 1 \\
3 / 7 \\
1 / 5 \\
5 / 8\end{array}$ & $\begin{array}{l}\overline{0} \\
0 / 1 \\
0 / 2 \\
1 / 1\end{array}$ & $\begin{array}{l}\overline{-} \\
1 / 2 \\
1 / 5\end{array}$ \\
\hline
\end{tabular}

*Numerator-number responding; denominator_number exposed. 
TABLE 3

Number of SubJeCtS SHOWing $10 \%$ INCREASE IN CC/TLC AND CV/VC*

\begin{tabular}{|c|c|c|c|c|c|c|}
\hline \multirow{2}{*}{ Occupation } & \multicolumn{3}{|c|}{$C C / T L C$} & \multicolumn{3}{|c|}{$C V / V C$} \\
\hline & Smokers & Ex-smokers & Non-smokers & Smokers & Ex-smokers & Non-smokers \\
\hline \multirow{4}{*}{$\begin{array}{l}\text { Picking } \\
\text { Carding } \\
\text { Spinning } \\
\text { Weaving and } \\
\text { warping }\end{array}$} & $0 / 1$ & - & 一 & $0 / 1$ & - & - \\
\hline & $2 / 7$ & $0 / 1$ & - & $2 / 7$ & $0 / 1$ & - \\
\hline & $2 / 5$ & $0 / 2$ & $0 / 2$ & $2 / 5$ & $0 / 2$ & $0 / 2$ \\
\hline & $1 / 8$ & $0 / 1$ & $1 / 5$ & $3 / 8$ & $0 / 1$ & $3 / 5$ \\
\hline
\end{tabular}

*Numerator-number responding; denominator-number exposed.

The vast majority of the subjects, namely 20 , exhibited less than $3 \%$ variability. When the MMF was examined, none of the patients before shift and only one after shift demonstrated more than $15 \%$ variability. The smokinghabits of the population are shown in Table 1.

Six men and three women showed a decline of $10 \%$ in $\mathrm{FEV}_{1}$ during the shift. Their smoking habits and work place are shown in Table 2. As can be seen from the table, positive responses occurred not only in the carders but also among the weavers and spinners. All nine of these subjects demonstrated a $15 \%$ decrease in MMF. Three additional subjects, one man and two women, developed a $15 \%$ decrease in MMF but no change in their $\mathrm{FEV}_{1}$ (Table 2).

There was a $10 \%$ increase in CC/TLC in three men and in three women. These data are shown in Table 3. When $\mathrm{CV} / \mathrm{VC}$ was considered, five men and five women showed a $10 \%$ increase (Table 3). It is generally accepted that CC/TLC is more sensitive than CV/VC and that such sensitivity may be conferred by an increase in the residual volume (RV). However, in those four patients in whom the $\mathrm{CV} / \mathrm{VC}$ was more sensitive, the RV was unchanged in two despite an increase in TLC and in the other two, RV actually decreased slightly.

Five subjects whose $\mathrm{FEV}_{1}$ did not decline by $10 \%$ showed an increase of $10 \%$ or more in either $\mathrm{CV} / \mathrm{VC}$ or CC/TLC. In contrast, however, there were four patients who showed at least a $10 \%$

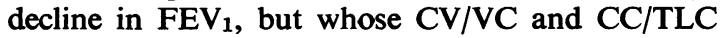
remained essentially unchanged.

\section{Comment}

In this pilot study, byssinosis was defined by changes in one or more tests of pulmonary function. This was done to avoid the highly subjective questionnaire definition of low-grade byssinotics in whom no measurable reaction occurs (Braun et al., 1973) and the falsely negative cases in workers who do not report symptoms but who demonstrate decrements in pulmonary function (Zuskin et al., 1969). It also eliminates those who have chronic symptoms of cough and chest tightness (breathlessness) owing to smoking from those whose symptoms are due to more advanced (Grade III) byssinosis.

A learning effect cannot be responsible for the changes which we found. First, such an effect would be in the opposite direction from those changes with which we are concerned. Secondly, all our subjects had performed these forced expiratory volume manoeuvres as part of a routine testing programme at the mill and were familiar with the procedures at the time of the study.

Likewise, diurnal variation in ventilatory capacity cannot be the cause of the changes. Variation in ventilatory capacity during the day shift in several studies (Guberan et al., 1969; Walford et al., 1966; Lapp et al., 1972) was in the opposite direction, and during the night shift little or no change occurred. Only in the afternoon was there a decrease and its magnitude (approximately $2 \%$ ) was considerably less than the change which we accepted as clinically significant. Diurnal variation in closing volume has not been demonstrated in a small group of subjects (McFadden, Holmes, and Kiker, 1975).

It appears from this pilot study that $\mathrm{CV}$ would be no more sensitive than the $\mathrm{FEV}_{1}$ in the detection of subjects with byssinosis. Although there were several subjects who demonstrated an increase in CV/VC or CC/TLC without a corresponding decrement in $F E V_{1}$, there was an almost equal number of subjects who showed a decline in $\mathrm{FEV}_{1}$ but whose CV/VC and CC/TLC did not change appreciably. Such a discrepancy suggests that different mechanisms may be at work producing the alteration in these tests, and further investigations to delineate these mechanisms would be valuable.

CV/VC appears to be more sensitive than $\mathrm{CC} /$ TLC in this group of cotton mill workers. This finding may be related to lack of the usual increase in RV in such situations. A similar finding was observed in another occupationally exposed group. In 82 working coal miners the mean closing volume was more sensitive to years spent working underground 
than the CC/TLC (Lapp et al., submitted for publication).

$\mathrm{CV}$ is technically more difficult and takes five to six times as long to perform as does conventional spirometry. Moreover, measurement of $\mathrm{CV}$ requires expensive equipment, a well-trained skilled technician, and measurement of the tracing is subject to appreciable inter- and intra-observer variation. A greater number of subjects are unable to perform the more complex respiratory manoeuvres that constitute the test.

Repeated closing volume manoeuvres are subject to greater variability than forced expiratory volume manoeuvres. We chose $10 \%$ as a clinically significant change in the values of $\mathrm{CV} / \mathrm{VC}$ and $\mathrm{CC} /$ TLC. We selected this value based on the studies of Collins et al. (1973), using a foreign gas technique, in which the variability of repeated closing volume manoeuvres was approximately $10 \%$. We recognized that our selected value was lenient and that the significance of such a change could be questioned. This was confirmed in our own laboratory using the resident gas technique described earlier and a small group of highly motivated and well-trained volunteers; the variability of the CV/VC was $21 \%$ and CC/TLC, $12 \%$ (unpublished observations). McFadden et al. (1975) in a paper published after the completion of this study used the resident gas technique in a similar structured setting and reported coefficients of variation for these measurements of approximately $25 \%$ and $9 \%$ respectively. It is doubtful if untrained subjects in a field setting could be coached to maintain the highly standardized techniques that were required in these research facilities. Had a change of $40 \%$ in $\mathrm{CV} / \mathrm{VC}$ been required as an indication of byssinosis only five patients would have been identified and all of these demonstrated clinically significant changes in one of the spirometric tests.

For CV to be useful in routine detection of byssinosis, it would have to bemoresensitive than the FEV $_{1}$. Our experience in this limited study suggests that $\mathrm{CV}$ is less practical and no more sensitive than the FEV 1 . Although further studies to confirm this impression are desirable, we are hesitant to initiate them because of the problems in reproducing closing volume measurements. In contrast to $\mathrm{CV}$, the MMF appears more sensitive than the FEV 1 . It requires no additional equipment and little additional time for measurement. Our results suggest that a larger trial comparing the sensitivity of the $\mathrm{FEV}_{1}$ and the MMF in the evaluation of byssinosis is warranted.

\section{References}

Braun, D. C., Jurgiel, J. A., Kaschak, M. C., and Babyak, M. A. (1973). Prevalence of respiratory signs and symptoms among US cotton textile workers. Journal of Occupational Medicine, 15, 414-419.

Buist, A. S. (1973). Early detection of airways obstruction by the closing volume technique. Chest, 64, 495-499.

Collins, J. V., Clark, T. J. H., McHardy-Young, S., Cochrane, G. M., and Crawley, J. (1973). Closing volume in healthy non-smokers. British Journal of Diseases of the Chest, 67, 19-27.

Guberan, E., Williams, M. K., Walford, J., and Smith, M. M. (1969). Circadian variation of FEV in shift workers. British Journal of Industrial Medicine, 26, 121-125.

Lapp, N. J., Block, J., Boehlecke, B., Lippman, M., Morgan, W. K. C., and Reger, R. B. Closing volume in coal miners. (Submitted for publication.)

- Hankinson, J. L., Burgess, D. B., and O'Brien, R. (1972). Changes in ventilatory function in coal miners after a work shift. Archives of Environmental Health, 24, 204-208.

Leuallen, E. C. and Fowler, S. W. (1955). Maximal midexpiratory flow. American Review of Tuberculosis, 72, 783-800.

McCarthy, D. and Milic-Emili, J. (1973). Closing volume in asymptomatic asthma. American Review of Respiratory Diseases, 107, 559-570.

_- Spencer, R., Greene, R., and Milic-Emili, J. (1972). Measurement of 'closing volume' as a simple and sensitive test for early detection of small airway disease. American Journal of Medicine, 52, 747-753.

McFadden, E. R., Holmes, B., and Kiker, R. (1975). Variability of closing volume measurements in normal man. American Review of Respiratory Disease, 111, 135-140.

, Kiker, R., Holmes, B., and deGroot, W. J. (1974). Small airway disease. American Journal of Medicine, 57, 171-182.

National Heart and Lung Institute. (1973). Suggested Standardized Procedures for Closing Volume Determination. Bethesda, Maryland.

Roach, S. A. and Schilling, R. S. F. (1960). A clinical and environmental study of byssinosis in the Lancashire cotton industry. British Journal of Industrial Medicine, 17, 1-9.

Walford, J., Lammers, B., Schilling, R. S. F., van den Hoven van Genderen, D., and van der Veen, Y. G. (1966). Diurnal variation in ventilatory capacity. British Journal of Industrial Medicine, 23, 142-148.

Zuskin, E., Wolfson, R. L., Harpel, G., Welborn, J. W., and Bouhuys, A. (1969). Byssinosis in carding and spinning workers. Archives of Environmental Health, 19, 666-673.

Received for publication 19 November 1974. Accepted for publication 24 January 1975. 
Writing Scientific Papers in English. By M. O'Connor and F. P. Woodford. (\$7.95). Amsterdam: Elsevier/ Excerpta Medica/North-Holland. 1975.

Some years ago I was asked to comment on a draft paper with the intriguing title ' $A$ hygienic standard for chrysotile asbestos dust'. At dinner that evening I mentioned this to a colleague, 'Hygienic standard', he mused, 'a sterilized lamp-post, perhaps, for well-bred dogs'. There is no reason why nouns should not be used adjectivally, although conversion of the modifying noun into an adjective may change its meaning. 'Protein iron' states the authors of Writing Scientific Papers in English is quite acceptable, but this must not be carried too far. 'Adult sheep muscle protein iron' impedes understanding and may even defy it.

The writing of good scientific papers, however, is not simply a matter of unsplitting infinitives, attaching lonely participles, and that sort of thing. I have always found that colleagues are very willing to help in this way. Right at the beginning of this excellent book it is correctly stated, 'The most troublesome blocks to writing a good scientific paper are conceptual and procedural'. Having thus clearly identified the main problem the writers produce useful advice on how to solve it. They suggest that the author should start by writing a 'working abstract', that will never appear but which will serve to clear his mind and rearrange his ideas. 'Clarity and the orderly arrangement of ideas are far more important than perfect grammatical form' is a maxim which might well be hand written at the top of every working abstract and penultimate draft.

Similarly they give the obvious but necessary advice that the aim of the writer should be to awaken interest rather than stifle it with fussy detail. Everyone must have read or listened to a paper in which the author sought to cover himself against all criticism when he need not have bothered, for his critics and others had given up, either turning their minds to other things or else falling asleep.

After much useful and frequently neglected advice on writing and revising the paper and on preparation of tables, graphs, and illustrations there is a chapter on responding to the editor. In my experience, the great majority of authors including the inexperienced and the eminent, appreciate the comments of the editor and the referees. Nevertheless a few, including the inexperienced and some eminent, react arrogantly and aggressively. The writers of this book rightly say that 'Criticism will nearly always have been made dispassionately, for the sake of the journal's reputation and the furthering of science, not with the aim of discomforting you or denigrating your work. Most referees are impartial in their assessment of papers submitted to them, and are too busy to spend time and effort inventing trivial objections to your paper'.

Every scientific author should convert his trio of Fowler, Roget, and the Concise Oxford Dictionary into a quartet with this practical and clearly written book. The useful appendix on clumsy phrases to avoid has helped me in writing this short review.

W. R. LEE

\section{NOTICES}

\section{Society of Toxicology}

The annual scientific meeting of the Society of Toxicology will be held at the Marriott Hotel in Atlanta, Georgia from 14 to 18 March 1976. Further information may be obtained from: Dr Gale C. Boxill, Secretary, Society of Toxicology, Wyeth Laboratories Inc., Box 861, Paoli, Pennsylvania 19301, USA.

International Radiation Protection Association

The IVth international congress will be held at the Paris Convention Centre, France from 24 to 30 April 1977.

The theme will be 'Radiation protection as an example of action against modern hazards' and all aspects of protection will be discussed. The languages of the congress will be French and English.

There will be an exhibition of techniques and equipment that have been developed in various countries for the protection of workers, the population, and the environment.

Further information may be obtained from: Mr Gilbert Bresson, General Secretary IRPA IVth International Congress, B.P. 33, 92260-Fontenay-aux-Roses, France.

\section{Alcoholism and Drug Dependence}

The third international conference will be held in Liverpool from 4 to 9 April 1976.

Papers will be presented by those involved in the fields of alcoholism and drug dependence including educationalists, psychiatrists, physicians, psychologists, sociologists as well as representatives from social work agencies both statutory and voluntary.

Further information may be obtained from: Miss M. C. Smith, Conference Secretary, B15 The Temple, Dale Street, Liverpool L2 5RU.

\section{Erratum}

Pilot study of closing volume in byssinosis by $\mathbf{R}$. P. Fairman, J. Hankinson, H. Imbus, N. L. Lapp, and W. K. C. Morgan British Journal of Industrial Medicine 1975 , 32. Line 1, column 1, page 236 should be printed at the bottom of column 1, page 235 . It should therefore read: The study was carried out in a North Carolina cotton mill in which byssinosis is still a problem. Previous surveys using the Medical Research Council (MRC) questionnaire, and standard tests of ventilatory capacity before and after a shift ... 